\section{Business and} Management

\section{ATTITUDES AND PERCEPTIONS REGARDING ENTREPRENEURSHIP AROUND THE WORLD: A CLUSTER} ANALYSIS APPROACH

Alcina Nunes, Carlos Balsa

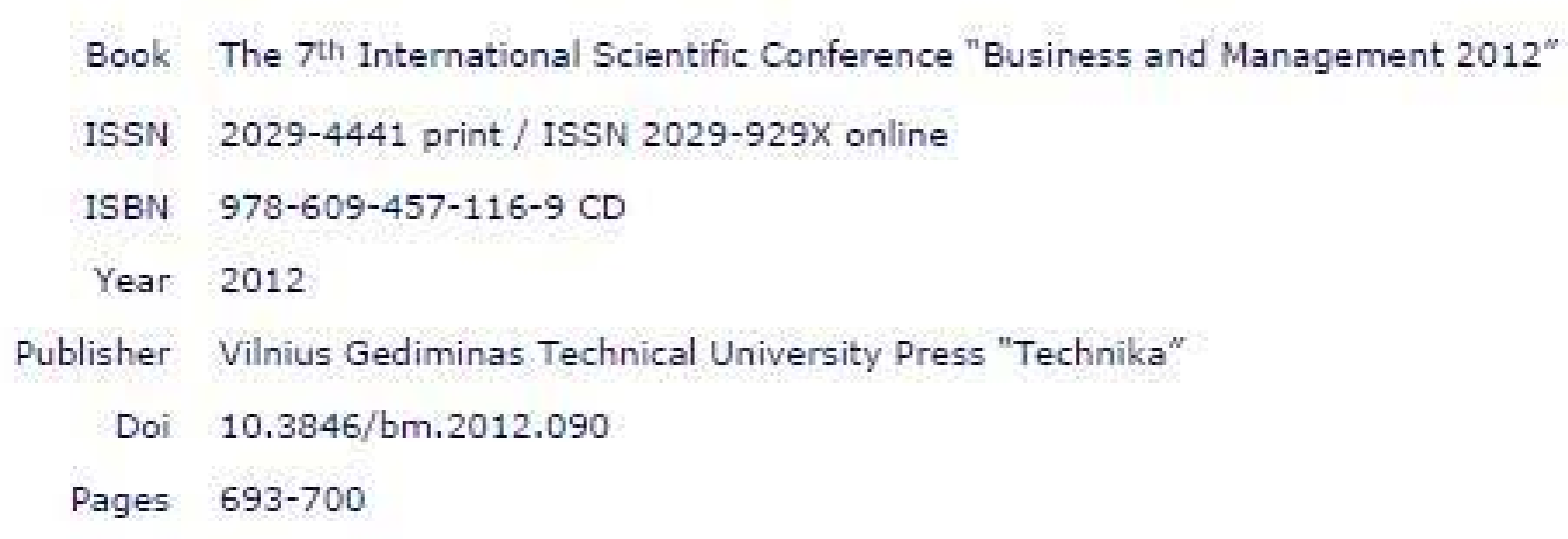

View full text in PDF format

\section{Abstract}

Nowadays it is believed that entrepreneurship could be a driving force in growth and development. For the achievement of a relevant national entrepreneurship rate the social and economic business environment can be crucial. However, despite the international attention given to entrepreneurship, it is not known if it is a global phenomenon or if there are particular regions where the entrepreneurial activity is specially recognized by society. Applying cluster analysis statistical techniques to a dataset gathered by the Global Entrepreneurship Monitor (GEM) and that includes, in 2010, 59 countries this paper intends to identify groups of countries with the same population attitude and perception regarding entrepreneurship.

Keywords: entrepreneurship, business environment, attitudes, perceptions, cluster analysis, GEM. 


\title{
ATTITUDES AND PERCEPTIONS REGARDING ENTREPRENEURSHIP AROUND THE WORLD: A CLUSTER ANALYSIS APPROACH
}

\author{
Alcina Nunes ${ }^{1}$, Carlos Balsa ${ }^{2}$ \\ Polytechnic Institute of Bragança, Campus de Sta Apolónia, Apartado 1134, 5301-857, Bragança, Portugal \\ Email: ${ }^{1}$ alcina@ipb.pt; ${ }^{2}$ balsa@ipb.pt
}

\begin{abstract}
Nowadays it is believed that entrepreneurship could be a driving force in growth and development. For the achievement of a relevant national entrepreneurship rate the social and economic business environment can be crucial. However, despite the international attention given to entrepreneurship, it is not known if it is a global phenomenon or if there are particular regions where the entrepreneurial activity is specially recognized by society. Applying cluster analysis statistical techniques to a dataset gathered by the Global Entrepreneurship Monitor (GEM) and that includes, in 2010, 59 countries this paper intends to identify groups of countries with the same population attitude and perception regarding entrepreneurship.
\end{abstract}

Keywords: entrepreneurship, business environment, attitudes, perceptions, cluster analysis, GEM.

Jel classification: L26, C38

\section{Introduction}

Entrepreneurship is a multidimensional concept that does not generate a consensual definition. An important distinction is made between an occupational and a behavioural notion of entrepreneurship. The former refers to individuals owning and managing a business for their own account and risk, while the latter focuses on entrepreneurial behavior in the sense of seizing an economic opportunity (Wennekers 2006; Sternberg, Wennekers 2005). Following this last notion it is becoming of general agreement that attitudes towards entrepreneurship are determinant factors when deciding to be an entrepreneur (Guerrero et al. 2006).

The conviction that entrepreneurship is about people has empirical evidences. Arenius and Minniti (2005) have demonstrated that the perception of opportunities, the confidence about one's own skills and knowing other entrepreneurs are some important individual factors in the explanation of entrepreneurship activities across countries. Also Koellinger et al. (2007) found strong evidence that subjective, and often biased, perceptions have a crucial impact on business start-up even if the correlation between the reported level of entrepreneurial confidence and the approximate survival chances of nascent entrepreneurs across countries is negative. These results are important in the context of a set of new definitions of entrepreneurship like the one suggested by Acs and Szerb (2010), which define entrepreneurship as "a dynamic interaction of entrepreneurial attitudes, entrepreneurial activity, and entrepreneurial aspi- ration that vary across stages of economic development", or the one integrated in a more subjectivist theory of entrepreneurship, which brings together elements of individual creativity, discovery, surprise and learning (Mahoney, Michael 2005; Kor et al. 2007). Aditionally, several models

It is sometimes argued that nations differ in their underlying entrepreneurial spirit (Blanchflower et al. 2001) so in recent years more researchers start being interested in the behavioural branch of entrepreneurship across countries and regions. According to Bosma and Schutjens (2011), referring some of the international literature on the subject, it is now widely recognized that regional variation in entrepreneurship is significant and persistent, and often even exceeds national differences. This applies to both entrepreneurial attitude and actual entrepreneurial activity. See, for example, Bosma et al. (2009) and Grilo and Thurik (2006) which reached the same conclusion using different data. Data gathered by the Global Entrepreneurship Monitor (GEM) and Eurobarometer, respectively. Freytag and Thurik (2007) emphasize that the relative stability of differences in entrepreneurial activity across countries suggests that other than economic factors are at play.

Following the line of thought presented above, this is, accepting as true that individual attitudes and perceptions regarding entrepreneurship can influence entrepreneurial activity; this research work tries to find groups of countries that share similar entrepreneurship's attitudes and perceptions. Ap- 
plying a cluster analysis statistical methodology to the GEM dataset the main goal is to find some evidence that a regional pattern of attitudes and perceptions exists. Although this methodology is not a common one has been used in entrepreneurship analysis. See the examples of Becker et al. (2011), Cordon et al. (2008), Gartner (2002) and Barr et al. (1980), for several entrepreneurship topics namely the relation between attitudes, perceptions and entrepreneurship.

Note that cluster analysis should be considered an exploratory data-analysis technique (StataCorp 2009). According to Everitt (1993) this methodology is intended largely for generating rater than testing hypothesis. This idea drives its application in the present analysis. The paper aims to show that different world regions present different social contexts and backgrounds to the economic business environment. It is intended to divide the set of analysed countries in groups that share similar attitudes and perceptions regarding entrepreneurship. This is particularly important not only because the achievement of a relevant national entrepreneurship rate depends on the social and economic business environment but also because, despite the international attention given to entrepreneurship, it is not known if it is a global phenomenon or if there are particular regions where the entrepreneurial activity is specially recognized by society.

The paper is presented as follows. Next section presents the GEM dataset and the selection of variables that defines attitudes and perceptions regarding entrepreneurship. The section also presents some variable analysis. In section 3 a brief description of the methodology is presented. The cluster methodology results, and respective discussion, can be observed in section 4 . Section 5 concludes.

\section{Dataset and variables}

The Global Entrepreneurship Monitor (GEM) is a research program, initiated in 1998 as a joint research initiative of Babson College in Wellesley (USA) and the London Business School, that focuses on collecting annual harmonized data on entrepreneurship considered as a major driver of economic growth. The data is gathered to facilitate cross national comparisons, for an increasing number of countries, regarding several entrepreneurship indicators (Reynolds et al. 2005; Stenberg, Wennekers 2005). The number of participating countries has risen from 10 in 1999 to consistently above 30 from 2002 onwards. In 2010 is possible to compute entrepreneurship indicator for 59 economies all over the world as can be ob- served - and collected - in the GEM website (http://www.gemconsortium.org/default.aspx). The "GEM countries" consist on a sample of developed countries - the G8 countries, most OECD countries and almost all of the countries in European Union - and a smaller group of developing countries in Latin America, Africa and Asia.

Nowadays, as referred in the previous section, more economists are attempting to measure entrepreneurial spirit across countries in a regional perspective. Given the possibility to compare indicators across countries all over the world, data from GEM have been used to create indicators on regional entrepreneurial activity. These start being applied in entrepreneurship spatial analysis, namely in the process of mapping entrepreneurial activity and entrepreneurial attitudes across regions (e.g. Bosma, Schutjens 2011, 2009, 2007).

The GEM's Adult Population Surveys provide standardized data on each country population's entrepreneurial preferences, capacities and activities since it is believed that a country's level of entrepreneurial activity is the result of its population's assessments of entrepreneurial opportunities and entrepreneurial motivations and capacities (Sternberg, Wenneker 2005). This belief assumes a particular importance in an entrepreneurship analysis if emphasis is put is the Kirzner's (1979) definition of entrepreneur. According to the author, entrepreneur is the one who perceives and pursues economic opportunities in the face of uncertainty.

Five of the most important indicators computed to measure each country perception and attitude regarding entrepreneurship are the following ones (Bosma et al. 2009):

- Entrepreneurship as a desirable career choice: percentage of 18-64 population who agree with the statement that in their country, most people consider starting a business as a desirable career choice;

- High status successful entrepreneurship: percentage of 18-64 population who agree with the statement that in their country, successful entrepreneurs receive high status;

- Media attention for entrepreneurship: percentage of 18-64 population who agree with the statement that in their country, you will often see stories in the public media about successful new businesses;

- Perceived capabilities: percentage of 1864 population who believe to have the required skills and knowledge to start a business; 
- Perceived opportunities: percentage of 1864 who see good opportunities to start a firm in the area where they live.

The 2010 results for the above five indicators, are summarised in Table 1, where the rank of the 10 countries with the highest/lowest values, by indicator, are presented.

Table 1. Rank of the countries with the 10 highest and lowest values for the GEM's indicators of attitudes and perceptions regarding entrepreneurship

\begin{tabular}{|c|c|c|c|c|c|c|c|c|c|}
\hline \multicolumn{2}{|c|}{$\begin{array}{c}\text { Entrepreneurship as } \\
\text { Desirable Career } \\
\text { Choice }\end{array}$} & \multicolumn{2}{|c|}{$\begin{array}{l}\text { Media Attention for } \\
\text { Entrepreneurship }\end{array}$} & \multicolumn{2}{|c|}{$\begin{array}{c}\text { High Status } \\
\text { Successful } \\
\text { Entrepreneurship } \\
\end{array}$} & \multicolumn{2}{|c|}{$\begin{array}{c}\text { Perceived } \\
\text { Opportunities }\end{array}$} & \multicolumn{2}{|c|}{$\begin{array}{c}\text { Perceived } \\
\text { Capabilities } \\
\end{array}$} \\
\hline Country & $\%$ & Country & $\%$ & Country & $\%$ & Country & $\%$ & Country & $\%$ \\
\hline \multicolumn{10}{|c|}{ TOP 10 - HIGHEST VALUES } \\
\hline $\begin{array}{l}\text { Ghana } \\
\text { G }\end{array}$ & 91 & Malaysia & 88 & Tunisia & 93 & $\begin{array}{l}\text { Uganda } \\
\text { Ug }\end{array}$ & 81 & Uganda & 87 \\
\hline Colombia & 89 & Uganda & 82 & Saudi Arabia & 92 & Zambia & 81 & Trin. \& Tobago & 83 \\
\hline Tunisia & 89 & Brazil & 81 & Ghana & 91 & Ghana & 76 & Jamaica & 80 \\
\hline Chile & 87 & Peru & 81 & Egypt & 89 & Saudi Arabia & 76 & Vanuatu & 80 \\
\hline Saudi Arabia & 87 & Ghana & 79 & Finland & 87 & Vanuatu & 74 & Zambia & 78 \\
\hline Jamaica & 85 & South Africa & 79 & Uganda & 87 & Peru & 71 & Ecuador & 77 \\
\hline Netherlands & 85 & Saudi Arabia & 78 & Iran & 85 & Trin. \& Tobago & 69 & Bolivia & 6 \\
\hline Palestine & 85 & Taiwan & 78 & Jamaica & 85 & Colombia & 68 & Peru & 76 \\
\hline Ecuador & 83 & Tunisia & 78 & Angola & 83 & Angola & 67 & Ghana & 75 \\
\hline rin. \& Tob- & 83 & China & 77 & Palestine & 83 & Sweden & 66 & Angola & 73 \\
\hline \multicolumn{10}{|c|}{ TOP 10 - LOWEST VALUES } \\
\hline Japan & 28 & Vanuatu & 34 & Croatia & 50 & Japan & 6 & Japan & 14 \\
\hline Finland & 46 & Greece & 35 & Belgium & 51 & Korea (South) & 13 & Russia & 23 \\
\hline Iceland & 51 & Italy & 38 & Japan & 52 & Greece & 16 & Malaysia & 24 \\
\hline United Kingdom & 51 & Spain & 41 & Taiwan & 58 & Romania & 18 & Taiwan & 26 \\
\hline Ireland & 52 & Croatia & 42 & Guatemala & 60 & Spai & 19 & Korea (South) & 9 \\
\hline Germany & 53 & Uruguay & 43 & Iceland & 61 & Portugal & 20 & France & 37 \\
\hline Slovenia & 53 & Guatemala & 44 & Uruguay & 62 & Russia & 22 & Romania & 38 \\
\hline Hungary & 55 & France & 45 & Costa Rica & 63 & Croatia & 23 & Finland & 40 \\
\hline Malaysia & 56 & Belgium & 46 & Mexico & 63 & Ireland & 23 & Israel & 40 \\
\hline Vanuatu & 56 & Chile & 46 & Spain & 63 & Italy & 25 & Norway & 40 \\
\hline
\end{tabular}

Regarding Table 1, entrepreneurship as a career choice ranges from $28 \%$ (Japan) to $91 \%$ (Ghana) for the target population. The conviction that there is a relationship between entrepreneurship and a high social status ranges from $50 \%$ (Croacia) and $93 \%$ (Tunisia). The statement that media pay particular attention to successful business stories ranges from $34 \%$ (Vanuatu) and $88 \%$ (Malaysia). The faith in individual entrepreneurship skills varies from $14 \%$ of the population (Japan) and $87 \%$ (Uganda). Finally, the numbers of individuals who perceive entrepreneurship opportunities in their country vary from $6 \%$ (Japan) and $81 \%$ (Uganda).

To measure entrepreneurship activity the GEM created the Total early-stage Entrepreneurial Activity (TEA) indicator. This indicator measures the percentage of 18-64 population who are either a nascent entrepreneur or owner-manager of a new business. The rank of the 10 countries with the highest and lowest percentages of entrepreneurial activity is presented in Table 2 .

Italy $(2.3 \%)$ and Japan $(3.3 \%)$ are the two countries with the lowest percentage of entrepreneurial activity. In opposition, Vanuatu (52.2\%) and Bolivia (38.6\%) are the countries with the highest values of entrepreneurial activity. Note that, with the exception of Japan, the countries with the lowest entrepreneurial activity rates are developed countries located in Europe. The countries with the highest entrepreneurial activity rates are countries in a development stage.

Table 2. Rank of the countries with the 10 highest and lowest values for the TEA

\begin{tabular}{|c|c|c|c|}
\hline \multicolumn{4}{|c|}{ Total early-stage Entrepreneurial Activity (TEA) } \\
\hline \multicolumn{2}{|c|}{ TOP 10 - HIGHEST VALUES } & \multicolumn{2}{|c|}{ TOP 10 - LOWEST VALUES } \\
\hline Country & $\%$ & Country & $\%$ \\
\hline Vanuatu & 52,2 & Italy & 2,3 \\
\hline Bolivia & 38,6 & Japan & 3,3 \\
\hline Ghana & 33,9 & Belgium & 3,7 \\
\hline Zambia & 32,6 & Denmark & 3,8 \\
\hline Angola & 32,4 & Russia & 3,9 \\
\hline Uganda & 31,3 & Germany & 4,2 \\
\hline Peru & 27,2 & Romania & 4,3 \\
\hline Ecuador & 21,3 & Spain & 4,3 \\
\hline Colombia & 20,6 & Portugal & 4,5 \\
\hline Brazil & 17,5 & Slovenia & 4,7 \\
\hline
\end{tabular}

Figure 1 presents a scatterplot matrix that shows the relation between the five selected indicators of attitude and perception and the indicator of entrepreneurial activity.

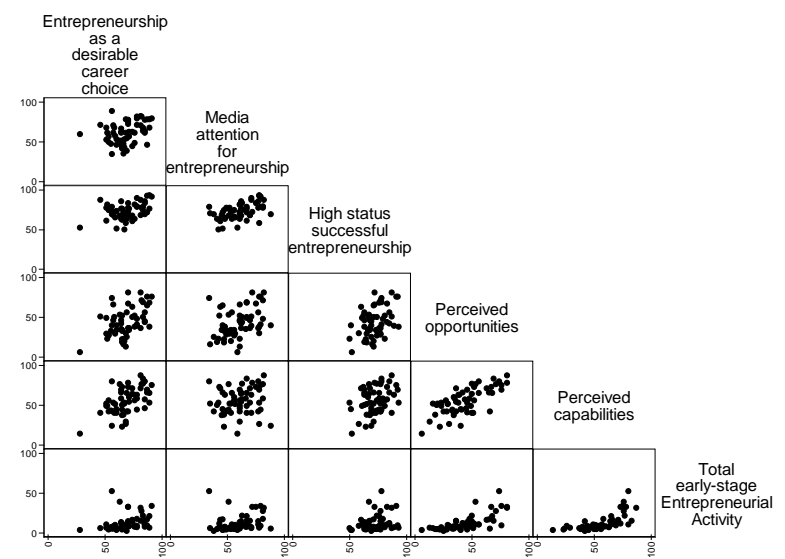

Fig.1. Matrix of GEM's indicators of attitudes and perceptions regarding entrepreneurship activity, for all considered countries

Depending on the selected pair of variables the relative location of countries seems to change. The countries are not identified however is possible to observe different relative shapes when displaying the relation between each pair of variables. This is particularly visible when the rate of entrepreneurial activity - TEA - is displayed relating each one of the other indicators. Still, the above matrix does not allow verifying the existence of groups characterized by similar characteristics when the indicators of attitudes and perceptions towards entrepreneurship are used altogether. The identification of similar groups when putting together all the five attitude and perception indicators needs a more complex statistical analysis $-\mathrm{a}$ cluster analysis, for example. 


\section{Brief introduction to cluster analysis}

The seminal work of Tryon (1939) introduced the cluster analysis. Such methodology is composed by a set of multivariate statistical methods that include different classification and optimization algorithms that intend to organize information concerning multiple variables and shape homogeneous groups.

In other words the cluster analysis develops tools and methods that, given a data matrix containing multivariate measurements on a large number of individuals (or objects); the aim is to build up some natural groups with homogeneous properties out of heterogeneous large samples. The groups or cluster should be as homogeneous as possible and the differences among the various groups as large as possible. The cluster analysis does not make conjectures about the number of groups or its structures - the groups are based on the similarities (or dissimilarities) among the groups characterized by different ways of calculating the "distance".

Several distinct methods can be used to measure the distance (or similarity) among the elements of a data matrix. They propose to infer about (i) the distance among observations coming from the same group and the distance among observations coming from different groups, (ii) the dispersion of observations within the same group and (iii) the density of the observations distribution inside and outside the groups. Being the adopted variables quantitative variables, the application of the Euclidian Distance method is advised (Giudici, Figini 2009). The distance is defined as the square root of the sum of the squared differences between the values of $i$ and $j$ for all the selected variables $(v=1,2, \ldots, p)$ :

$$
d_{i j}=\sqrt{\sum_{v=1}^{\rho}\left(X_{i v}-X_{j v}\right)^{2}},
$$

where $X_{i v}$ is the value of variable $v$ for country $i$ and $X_{j v}$ is the value of the variable $v$ for country $j$.

Besides the settlement of the distance among observations, computation method is still necessary to settle the computational method to calculate the distance among groups. Such step is particularly important when applying hierarchical methods for cluster definition. These methods allow obtaining a partition set associated with subsequent levels of aggregation among observations. This partition set can be represented graphically by dendrograms which are hierarchical structures with a shape similar to a tree shape. Indeed they represent partitions which leave from a more dis- aggregate observation division and come through a process of agglomeration that stops when all observation are joined in a same group.

Dendrograms can be obtained through the adoption of different techniques no one better than the other a priori, since it is not possible to select a best method for a given set of information. It is necessary to try different alternatives and compare the related results. In this research work, there were selected two techniques that could be distinguished by the fact that one of them - the complete linkage method - only demands the computation of the distance matrix among observations, and the other - the Ward method (Ward 1963) demands both the computation of the distance matrix among observations and the original matrix.

In the complete linkage method the distance between the two groups is defined as the maximum of distances between each observation belonging to the group and each observation belonging to other group:

$$
d\left(\pi_{1}, \pi_{2}\right)=\max _{x \in \pi_{1}, y \in \pi_{2}} d(x, y),
$$

where $x$ is a country belonging to group $\pi_{1}$ and $y$ is a country belonging to group $\pi_{2}$.

In the Ward's method an objective function is minimized to generate groups with a maximum internal cohesion and a maximum external separation. The objective function is defined as the sum of squares of the standard error of individual observations relatively to the mean of the group where they are classified. The distance between the two groups, $\pi_{1}$ and $\pi_{2}$, is difined as:

$$
d\left(\pi_{1}, \pi_{2}\right)=S P\left(\pi_{1} \cup \pi_{2}\right)-\left(S P\left(\pi_{1}\right)+S P\left(\pi_{2}\right)\right),
$$

where,

$$
S P(\pi)=\sum_{x \in \pi}\left|x-\overline{x_{\pi}}\right|^{2} .
$$

With the help of the dendrogram it is possible to identify the groups that should be considered in the analysis and consequently it is possible to apply optimization methods or non-hierarchical methods. These methods choose in advance the number of groups which will comprise all the observations. Then all the observations could be divided by the predefined groups and the best partition of the observations will be the one that optimizes the chosen criteria. One of the processes that could be applied is the k-means interactive partition method. The method follows the next steps: starts by dividing an initial partition of individuals by the number of clusters previously defined; computes for each cluster the respective centroid and the distances between each individual and the centroid of the various groups; transfers each individual to the cluster relatively to which 
presents the minor distance; re-computes the centroids of each cluster and repeats the previous steps until the moment each individual belongs to a stable cluster and, therefore, it is not possible to carry out more individual transfers among cluster. The method presents the disadvantage of limiting the search for an optimal partition of individuals since it restricts the number of predefined clusters. Still, it has the advantage of defining the regions belonging to each cluster as well as the distance of each group.

\section{Results of the cluster methodology}

The empirical application of the cluster analysis present in this research work follows the methodological steps suggested in the cluster analysis literature. As mentioned in the previous sections it is not know, a priori, which is the best classification method to apply. So, were applied two distinct algorithms for the countries' hierarchical classification - the complete and Ward's linkage methodology. The dendrograms obtained by the application of the complete and Ward's hierarchical cluster analysis can be observed in Figure 2 and Figure 3, respectively.

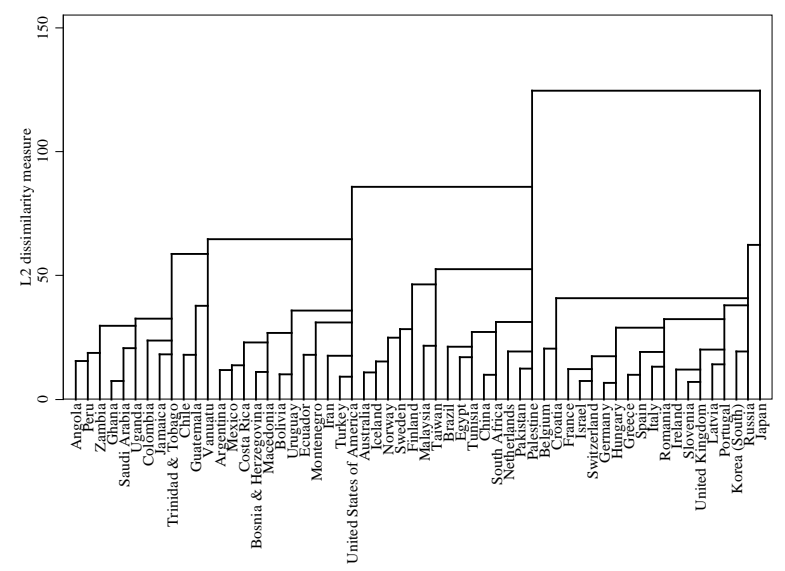

Fig.2. Complete linkage dendrogram

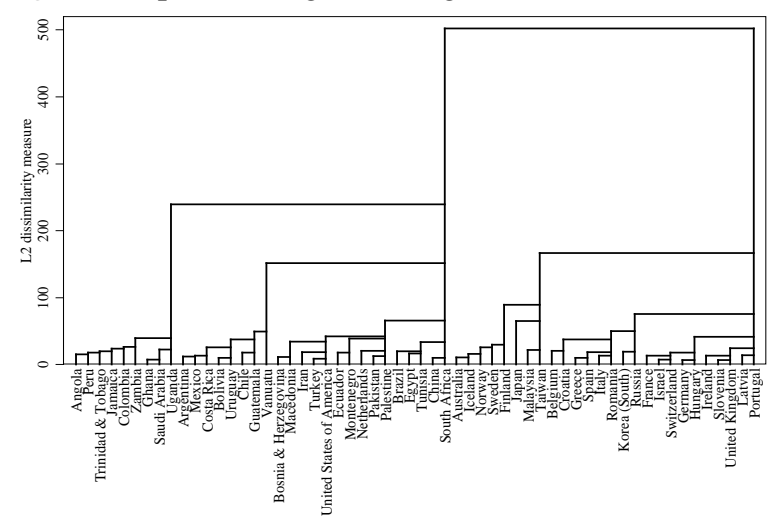

Fig.3. Ward's linkage dendrogram
Note that all indicators are measured with the same scale so there was no need of variable standardization. Denmark, that is the fourth country with the lowest rate of entrepreneurship activity (Table 2), has been withdrawn from the set of countries in analysis since the country presented missing values for some of the selected variables in 2010.

The two hierarchical cluster methods have produced different results, however is possible to understand that some countries present clear similarities with others - in both dendrograms is possible to see that some of the countries are close to each other independently of the method of distance computation. It is also possible to observe, in each dendrogram, the division of the all dataset in 4 or 5 main groups. Dendograms allow a first approach to the definition of the number of clusters expected in the optimization final solution. The visualization of the hypothetical country groups allows anticipating its optimal computational number as well as its composition.

The above results can be compared with the results computed by the non-hierarchical (or optimization) method chosen for the empirical analysis - the k-mean algorithm. This algorithm assumes that the number of groups (clusters) is previously known. However such assumption is rather unrealistic for most analysis problems since, normally, the data properties are not known. Thus the estimation of the number $\mathrm{k}$ of clusters is a frequent problem not only when applying the kmeans algorithm but also other methods of clusters generation.

The more intuitive and visual approach of the hierarchical methods offers clues to the estimation of a suitable number of clusters but is not totally convincing. The visual observation seems to suggest that the number of clusters should not be inferior to 4. Departing from this intuitive value was applied the Calinski-Harabasz pseudo F-test (Calinski, Harabasz 1974) - considered by Milligan and Cooper (1985) one of the best cluster stopping rules - for 4 or more clusters. The test indicates the division of countries in 4 groups is an adequate partition.

The results for the k-means methodology are presented in Table 3 (cluster's composition) and Table 4 (cluster's descriptive statistics).

The first group comprises 9 countries known as development countries. The second cluster contains the biggest number of countries (20). These are countries located, essentially, in Europe and with the highest stage of development. In this second group are some of the G-8 countries, for instance. The third cluster contains 10 countries 
characterised by their location - most of them are located in Latin America. The last cluster is the second biggest (19 countries) and seems to be the one that gathers the most distinct economies - located all over the world these countries are also in different stages of development and present different social, political, economical and legal environments. In cluster 4 is possible to find the US and Iran, for instance.

Table 3. Composition of the 4 clusters obtained using the k-means cluster methodology

\begin{tabular}{cccc}
\hline Cluster $\mathbf{1}$ & Cluster $\mathbf{2}$ & Cluster $\mathbf{3}$ & Cluster $\mathbf{4}$ \\
$\mathbf{9}$ countries & $\mathbf{2 0}$ countries & $\mathbf{1 0}$ countries & $\mathbf{1 9}$ countries \\
\hline Trinidad \& Tobago & Germany & Ecuador & United States of America \\
Zambia & Spain & Bosnia \& Herzegovina & Sweden \\
Colombia & Korea (South) & Bolivia & Iran \\
Angola & Latvia & Chile & Norway \\
Jamaica & Russia & Mexico & Finland \\
Saudi Arabia & Taiwan & Argentina & Palestine \\
Uganda & Slovenia & Costa Rica & Netherlands \\
Ghana & Croatia & Uruguay & Macedonia \\
Peru & Romania & Vanuatu & Montenegro \\
& United Kingdom & Guatemala & Pakistan \\
& Hungary & & Brazil \\
& Belgium & & Iceland \\
& Switzerland & & Australia \\
& France & & Egypt \\
& Portugal & & China \\
& Ireland & & South Africa \\
& Italy & & Malaysia \\
& Japan & & Tunisia \\
& Israel & Turkey \\
& Greece & & \\
\hline
\end{tabular}

With the descriptive statistics (minimum, maximum and mean) presented in Table 4 , is possible to define a statistical profile of the attitudes and perceptions regarding entrepreneurship, in each cluster. The statistical profiles can be compared with the mean entrepreneurial activity (TEA) computed for each cluster.

Table 4. Statistics for the 4 clusters obtained using the k-means cluster methodology (\%)

\begin{tabular}{|c|c|c|c|c|c|c|c|c|c|c|c|c|}
\hline & \multicolumn{3}{|c|}{ Cluster 1} & \multicolumn{3}{|c|}{ Cluster 2} & \multicolumn{3}{|c|}{ Cluster 3} & \multicolumn{3}{|c|}{ Cluster 4} \\
\hline & Min & Max & Mean & Min & Max & Mean & Min & Max & Mean & Min & Max & Mean \\
\hline $\begin{array}{c}\text { Entrepr } \\
\text { Desirable }\end{array}$ & 70 & 91 & 82,0 & 28 & 69 & 60.1 & 56 & 87 & 71.1 & 46 & 89 & 69,2 \\
\hline $\begin{array}{r}\text { Media } A \\
\text { Entrep }\end{array}$ & 67 & 82 & 75,3 & 35 & 78 & 50.9 & 34 & 63 & 50.6 & 56 & 88 & 69,0 \\
\hline $\begin{array}{l}\text { High Status Suc } \\
\text { Entrepreneur }\end{array}$ & 72 & 92 & 82,3 & 50 & 81 & 67.5 & 60 & 78 & 66.8 & 61 & 93 & 76,2 \\
\hline Perceived Opportunities & 56 & 01 & 71,7 & 6 & 40 & 25.1 & 38 & 74 & 54.7 & 34 & 66 & 43,6 \\
\hline Perceived Capabilities & 65 & 87 & 76,2 & 14 & 56 & 41.9 & 63 & 80 & 70.4 & 24 & 71 & 51,4 \\
\hline Tot & & 23.7 & & & 5.35 & & & 20.3 & & & 9.2 & \\
\hline
\end{tabular}

Cluster 1 presents the highest average values for all the indicators selected to assess attitudes and perceptions regarding entrepreneurship. It is also the cluster with the highest average value for the entrepreneurial activity rate - in this group of countries, on average, $23.7 \%$ of the $18-64$ population is either a nascent entrepreneur or ownermanager of a new business. In this group, $76.2 \%$ and $71.7 \%$, of the same population, perceive en- trepreneurship opportunities and capabilities, respectively. The association between entrepreneurship and a high social status and a desired career is made by, approximately $82 \%$ of the target population and $75 \%$ thinks the media give a special attention to the entrepreneurship topic.

The cluster with the second highest entrepreneurial activity rate on an early stage is cluster $3-$ $20.3 \%$ of the $18-64$ population is engaged in a new business activity. This group presents also the second average rates for some of the attitudes and perceptions indicators - perceived opportunities, perceived capacities and entrepreneurship as a desirable career choice.

The fourth computed cluster (cluster 4) is the more difficult to characterise - its dispersion in terms of characteristics makes the analysis problematic. It seems a group that collects the countries that do not had a place in the other groups than an actual homogeneous group.

The biggest cluster, in terms of the number of countries (cluster 2), presents both the lowest entrepreneurial activity rate (only $5.35 \%$ of the 1864 population is engaged in a nascent business activity) and the lowest average values for the five selected indicators. For example, on average only $25 \%$ of the 18-64 population perceive entrepreneurship opportunities and less than half perceive entrepreneurship capabilities. Remember that this group gathers, with only few exceptions, developed countries located in Europe.

\section{Conclusions}

Rhie (2009) referring Markham et al. (2002) stress the idea that are the perceptions of self-efficacy rather than objective ability that motivate individuals to demonstrate entrepreneurial behavior. As mentioned in the paper, the attitude towards entrepreneurship and the perception of capabilities and opportunities, for example, can drive the entrepreneurial activity in a particular economy. Morris (2011) in a report about high-growth entrepreneurs, using GEM data, found that they have little fear of failure and are among the most likely of those surveyed to start a business because they perceive that there is an opportunity to be exploited. However, despite the studies relating attitudes and perceptions to entrepreneurial activity, few are known about the spatial distribution of that attitudes and perceptions.

Using comparable cross-national data, covering a set of distinct world economies in 2010, and applying a cluster analysis has been possible to divide 58 countries in 4 similar groups of countries. A higher perception of opportunities and ca- 
pabilities is found mostly in non European and non high-income economies. Entrepreneurship as a career choice and associated to a high social status or the perception of a special attention given by the media to the entrepreneurship phenomena are also less likely to found in this segment of countries. These attitudes and perceptions towards entrepreneurship are most likely to be found in low and middle income countries located in Latin America, Africa and Asia.

As assumed this research work did not intended to test hypothesis but rather generate it, so even if it has been observed a positive relation between high positive rates for the five attitude and perception indicators and high entrepreneurial early-stage activity has not been tested any causal relationship.

\section{References}

Acs, Z.; Szerb, L. 2010. The Global Entrepreneurship and development Index (GEDI), DRUID Conference paper on Opening up Innovation: Strategy, Organization and Technology, London, United Kingdom.

Arenius, P.; Minniti, M. 2005. Perceptual variables and nascent entrepreneurship, Small Business Economics 24(3): 233-247. http://dx.doi.org/10.1007/s11187-005-1984-X

Barr, B. M.; Walters, N. M.; Fairbairn, K. J. 1980. The application of cluster analysis to entrepreneurial perception of regional economic environments, Environment and Planning A 12(8): 869-879. http://dx.doi.org/10.1068/a120869

Becker, K.; Kronthaler, F.; Wagner, K. 2011. The entrepreneurship potential within Swiss regions: a comparison based on cluster analysis, in Raposo, M. Smallbone, D.; Balaton, K.; Hortoványi, I. (Eds.). Entrepreneurship Growth and Economic Development: Frontiers in European Entrepreneurship Research. Edward Elgar Publishing Limited. Cheltnham: United Kingdom, 180-204.

Blanchflower, D. G.; Oswald, A.; Stutzer, A. 2001. Latent entrepreneurship across nations, European Economic Review 45(4-6): 680-691. http://dx.doi.org/10.1016/S0014-2921(01)00137-4

Bosma, N.; Schutjens, V. 2011. Understanding regional variation in entrepreneurial activity and entrepreneurial attitude in Europe, The Annals of Regional Science 47(3): 711-742. http://dx.doi.org/10.1007/s00168-010-0375-7

Bosma, N.; Schutjens, V. 2009. Mapping entrepreneurial activity and entrepreneurial attitudes in European regions, International Journal of Entrepreneurship and Small Business 7(8): 191-213. http://dx.doi.org/10.1504/IJESB.2009.022806

Bosma, N. S.; Acs, Z. J.; Autio, E.; Coduras, A.; Levie, J. 2009. Global Entrepreneurship Monitor 2008 Executive Report, Babson College, Universidad del Desarrollo and London Business School.
Bosma, N.; Schutjens, V. 2007. Patterns of promising entrepreneurial activity in European regions, Journal of Academic and Social Geography 98(5): 675686.

Calinski, T.; Harabasz, J. 1974. A dendrite method for cluster analysis, Communications in Statistics Theory and Methods 3(1): 1-27. http://dx.doi.org/10.1080/03610927408827101

Cardon, M. S.; Shinnar, R. S.; Eisenman, M.; Rogoff, E. G. 2008. Segmenting the population of entrepreneurs: a cluster analysis study, Journal of Developmental Entrepreneurship 13(3): 293-314. http://dx.doi.org/10.1142/S1084946708001009

Everitt, B. S. 1993. Cluster Analysis, John Wiley \& Sons: London.

Gartner, W. B. 2002. What are we talking about when we talk about entrepreneurship?, Journal of Business Venturing 5(1): 15-28. http://dx.doi.org/10.1016/0883-9026(90)90023-M

Giudici, P.; Figini, S. 2009. Applied Data Mining for Business and Industry, John Wiley \& Sons Ltd.: London. http://dx.doi.org/10.1002/9780470745830

Grilo, I.; Thurik, R. 2006. Latent and actual entrepreneurship in Europe and the US. Some recent developments, International Entrepreuneurship and Management Journal 1(4): 441-459. http://dx.doi.org/10.1007/s11365-005-4772-9

Guerrero, M.; Rialp, J.; Urbano, D. 2006. The impact of desirability and feasibility on entrepreneurial intentions: a structural equation model, International Entrepreneurship and Management Journal 4(1): 3550. http://dx.doi.org/10.1007/s11365-006-0032-x

Kirzner, I. M. 1973. Competition and Entrepreneurship, University of Chicago Press: Chicago.

Koellinger, P.; Minniti, M.; Schade, C. 2007. "I think I can, I think I can”: overconfidence and entrepreneurial behavior, Journal of Economic Psychology 28: 502-527. http://dx.doi.org/10.1016/j.joep.2006.11.002

Kor, Y. Y.; Mahoney, J. T.; Michael, C. 2007. Resources, capabilities and entrepreneurial perceptions, Journal of Management Studies 44(7): 1187-1212. http://dx.doi.org/10.1111/j.1467-6486.2007.00727.x

Mahoney, J. T.; Michael, S. C. 2005. A subjectivist theory of entrepreneurship, in, Alvarez, S; Agarwal, R.; Sorensen, O. (Eds), Handbook of Entrepreneurship, Kluwer: Boston, MA: 33-53.

http://dx.doi.org/10.1007/0-387-23622-8_3

Markman, G. D.; Balkin, D. B.; Baron, R. A. 2002. Inventors and new venture formation: the effect of general self-efficacy and regretful thinking, Entrepreneurship Theory and Practice 27(2): 149-165. http://dx.doi.org/10.1111/1540-8520.00004

Milligan, G. W.; Cooper, M. C. 1985. An examination of procedures for determining the number of clusters in a dataset, Psychometrika 50(2): 159-179. http://dx.doi.org/10.1007/BF02294245 
Morris, R. 2011. High-impact entrepreneurship global report, Center for High Impact Entrepreneurship at Endeavor.

Reynolds, P.D.; Bosma, N.; Autio, E.; Hunt, S.; de Bono, N.; Servais, I.; Lopez-Garcia, P.; Chin, N. 2005. Global Entrepreneurship Monitor: Data Collection Design and Implementation 1998-2003, Small Business Economics 24(3): 205-231.

http://dx.doi.org/10.1007/s11187-005-1980-1

Rhie, Z. A. 2009. Entrepreneurship as a career choice: an analysis of entrepreneurial self-efficacy and intention of university students, European Journal of Social Science 9(2): 338-346.

StataCorp. 2009. Stata Multivariate Statistics Reference Manual - Release 11, Stata Press Publication. College Station: Texas.
Sternberg, R.; Wennekers, S. 2005. Determinants and effects of new business creation using Global Entrepreneurship Monitor data, Small Business Economics 24(3): 193-203.

http://dx.doi.org/10.1007/s11187-005-1974-z

Tryon, R.C. 1939. Cluster Analysis, McGraw-Hill. New York.

Ward, J. 1963. Hierarchical Grouping to Optimize an Objective Function, Journal of American Statistical Association 58: 236-244.

Wennekers, A. R. M. 2006. Entrepreneurship at country level: economic and non-economic determinants: ERIM PhD Series Research in Management, Erasmus University of Rotterdam, Netherlands. 